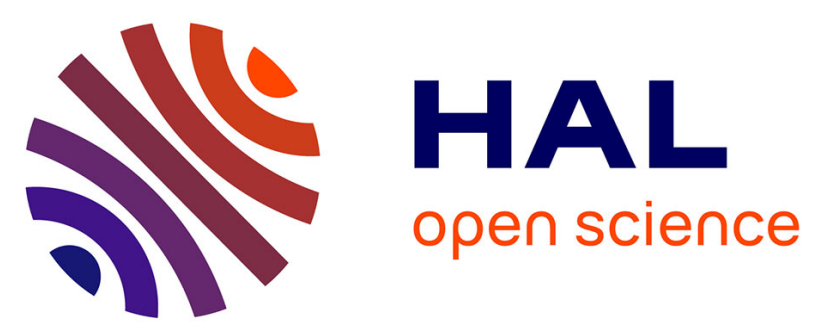

\title{
11CO2 positron emission imaging reveals the in-situ gas concentration profile as function of time and position in opaque gas-solid contacting systems
}

\author{
Jonathan Seville, Yimin Deng, Sarah Dawn Bell, Raf Dewil, Lise Appels,
} Renaud Ansart, Tom Leadbeater, David Parker, Huili Zhang, Andrew Ingram, et al.

\section{To cite this version:}

Jonathan Seville, Yimin Deng, Sarah Dawn Bell, Raf Dewil, Lise Appels, et al.. 11CO2 positron emission imaging reveals the in-situ gas concentration profile as function of time and position in opaque gassolid contacting systems. Chemical Engineering Journal, 2020, 404, pp.0. 10.1016/j.cej.2020.126507 . hal-02944486

\author{
HAL Id: hal-02944486 \\ https://hal.science/hal-02944486
}

Submitted on 21 Sep 2020

HAL is a multi-disciplinary open access archive for the deposit and dissemination of scientific research documents, whether they are published or not. The documents may come from teaching and research institutions in France or abroad, or from public or private research centers.
L'archive ouverte pluridisciplinaire HAL, est destinée au dépôt et à la diffusion de documents scientifiques de niveau recherche, publiés ou non, émanant des établissements d'enseignement et de recherche français ou étrangers, des laboratoires publics ou privés. 


\section{OATAO \\ Open Archive Toulouse Archive Ouverte}

\section{Open Archive Toulouse Archive Ouverte}

OATAO is an open access repository that collects the work of Toulouse researchers and makes it freely available over the web where possible

This is an author's version published in: http://oatao.univ-toulouse.fr/ 26578

Official URL : https://doi.org/10.1016/i.cej.2020.126507

\section{To cite this version:}

Seville, Jonathan and Deng, Yimin and Dawn Bell, Sarah and Dewil, Raf and Appels, Lise and Ansart, Renaud $\stackrel{5}{5}$ and Leadbeater, Tom and Parker, David and Zhang, Huili and Ingram, Andrew and Baeyens, Jan $11 \mathrm{CO} 2$ positron emission imaging reveals the in-situ gas concentration profile as function of time and position in opaque gas-solid contacting systems. (2020) Chemical Engineering Journal, 404. ISSN 1385-8947

Any correspondence concerning this service should be sent to the repository administrator: tech-oatao@listes-diff.inp-toulouse.fr 


\title{
${ }^{11} \mathrm{CO}_{2}$ positron emission imaging reveals the in-situ gas concentration profile as function of time and position in opaque gas-solid contacting systems
}

\author{
Jonathan Peter Kyle Seville ${ }^{\mathrm{a}, 1}$, Yimin Deng, ${ }^{\mathrm{b}, \mathrm{e}, 1}$, Sarah Dawn Bell ${ }^{\mathrm{a}}$, Raf Dewil ${ }^{\mathrm{b}}$, Lise Appels ${ }^{\mathrm{b}}$, \\ Renaud Ansart ${ }^{\mathrm{c}}$, Tom Leadbeater ${ }^{\mathrm{d}}$, David Parker ${ }^{\mathrm{a}}$, Huili Zhang ${ }^{\mathrm{e}}$, Andrew Ingram ${ }^{\mathrm{a}, *}$, \\ Jan Baeyens, ${ }^{\mathrm{e}, *}$ \\ ${ }^{a}$ School of Chemical Engineering, University of Birmingham, Birmingham B15 2TT, United Kingdom \\ ${ }^{\mathrm{b}} \mathrm{KU}$ Leuven, Department of Chemical Engineering, Process and Environmental Technology Lab, 2860 Sint-Katelijne-Waver, Belgium \\ ${ }^{c}$ Laboratoire de Génie Chimique, Université de Toulouse, CNRS, INPT, UPS, Toulouse, France \\ ${ }^{\mathrm{d}}$ University of Cape Town, Department of Physics, Cape Town, South Africa \\ ${ }^{\mathrm{e}}$ Beijing University of Chemical Technology, Beijing Advanced Innovation Centre of Soft Matter Science and Engineering, Beijing, Chaoyang District, 100029, China
}

\begin{abstract}
The in situ analysis of industrial processes, mostly conducted in opaque equipment is difficult. Whereas previously the positron emission technique was successfully applied to study the flow and mixing in gas-solid and liquid-solid systems using radio-active tracer particles, research on imaging a radio- active tracer gas is scarce.

The present paper demonstrates the use of a fully three-dimensional (3D) Positron Emission Tomography (PET) in imaging the adsorption of ${ }^{11} \mathrm{CO}_{2}$ tracer gas, while validating the measurement by conventional exit gas analysis. It will be demonstrated that PET can be used to measure the kinetics of high-pressure $\mathrm{CO}_{2}$ adsorption in situ, including the essential breakthrough and mass transfer zone characteristics. Such high-pressure operation is characteristic of pre-combustion $\mathrm{CO}_{2}$ capturing processes. It is expected that this work will foster further studies of gas-solid systems of adsorption, gas-solid catalysis, gas-solid hydrodynamics, and processes where the gas-solid interaction is of primary importance.
\end{abstract}

\section{Introduction}

Gas-solid contacting systems are widely used in the process industries, with gas-catalytic reactors and gas-solid adsorbers as important examples. Fixed-bed gas-catalytic reactors are often the first choice for the economical production of large amounts of products. The selective adsorption of gaseous components from a gas mixture is widely applied in air pollution control and finds increasing application in $\mathrm{CO}_{2}$ capture from combustion exhausts.

The complete understanding, design and operation of these heterogeneous processes however requires quantitative in situ data on the concentration of the target gas molecules, present as reactant or adsorbed gas) on the surface of the catalyst or adsorbent, respectively. Since the processes are commonly conducted in opaque vessels and generally at high temperatures and/or pressures, such processes are usually monitored only by measurement techniques on the process exit streams, hence providing no information on the evolution of the gas concentrations with time and position inside the gas-solid reactor or adsorber. Yet these detailed data are important to study intrinsic kinetics and transport phenomena, moreover required as input to

\footnotetext{
* Corresponding authors.

E-mail addresses: A.Ingram@bham.ac.uk (A. Ingram), Baeyens.J@gmail.com (J. Baeyens).

${ }^{1}$ Considered as equal principal authors.
} 


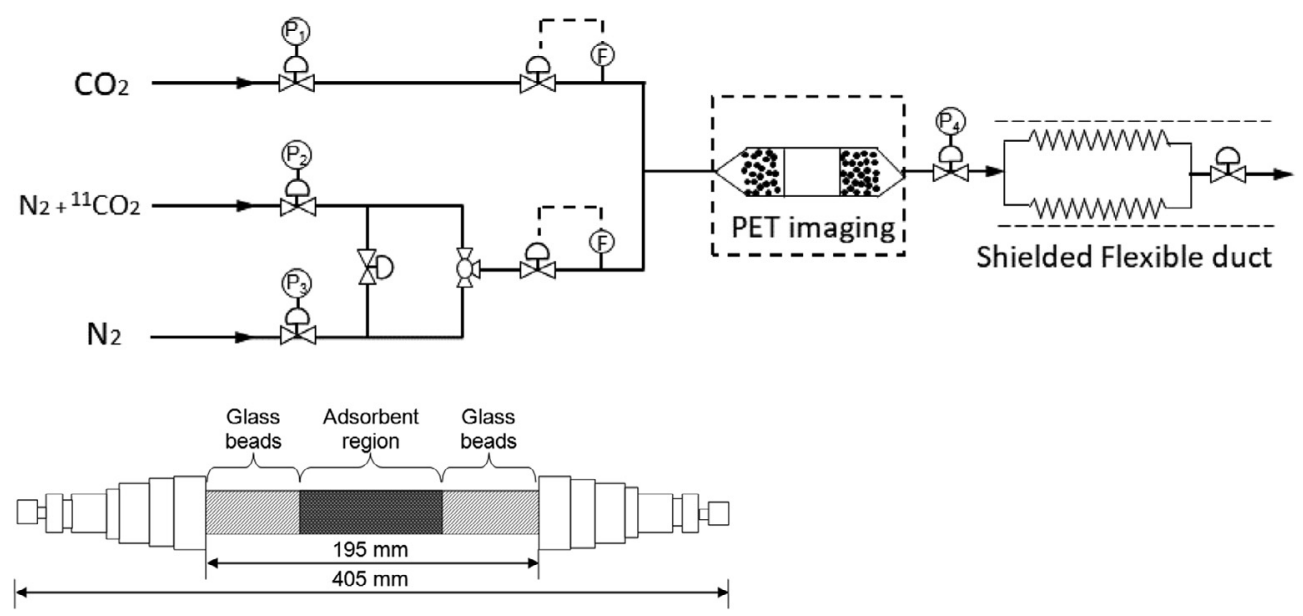

Fig. 1. Experimental set-up and detail of the adsorption column with adsorbent bed and glass beads packing ( $\mathrm{P}_{\mathrm{i}}$ : pressure control valves, $\mathrm{F}$ : mass flow rate measurements).
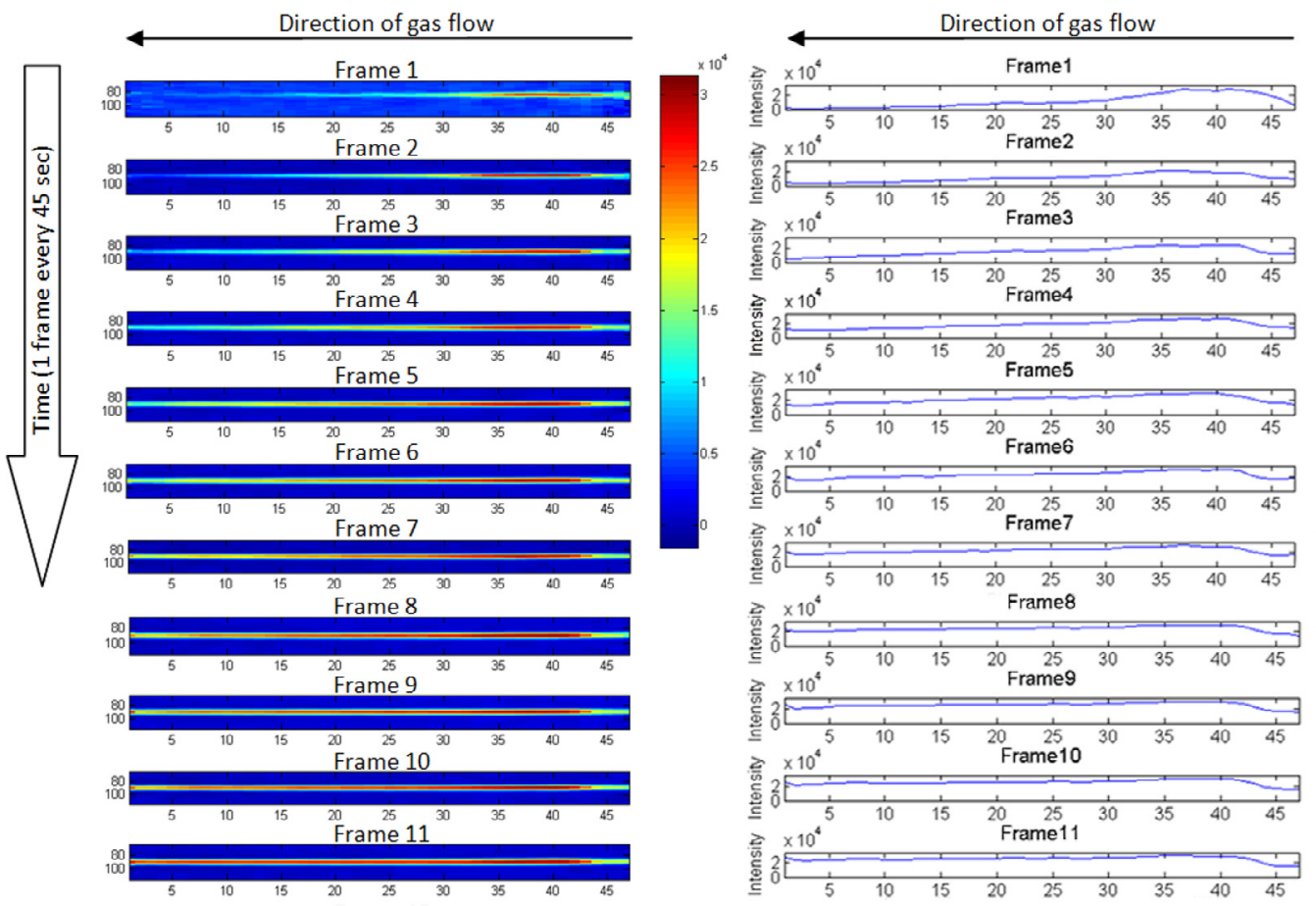

Fig. 2. Illustration of the ${ }^{11} \mathrm{CO}_{2}$ profiles from inflow to outflow in the Zeolite $13 \mathrm{X}$ packed bed for 11 consecutive image frames, each containing data acquired over $45 \mathrm{~s}$ [13]. Images are given in pixel-colour (left) or in intensity (counts per minute, cpm) data (right).

mathematical simulations of the processes under scrutiny. The development of monitoring techniques to provide in situ data from actual operations is required, and the use of radioactive labeled molecules was investigated for that purpose in the present research.

In the diagnosis and treatment of many diseases [1], functional radio-active tracer medical imaging is used to study physiological processes within the human body. Such clinical imaging can be adapted for industrial use, where process equipment is also of opaque nature and in situ analysis of processes is difficult. The Positron Imaging Centre (PIC) of the University of Birmingham uses positron emission [2-4] to study the flow and mixing in gas-solid and liquid-solid systems using radio-active tracer particles [5-12]. Research on the imaging of radioactive tracer gas is scarce. Such a technique enables non-intrusive observation of processes involving gases and thereby helps in understanding industrial operations such as sorption and reaction. Positron Emission Tomography (PET) has been applied to a limited extent, in fluidised beds $[13,14]$, in studying the fluid flow within porous rock
[15], and to analyse surface catalysis in car exhaust systems [16].

The objectives and novelty of the present research aim at developing and demonstrating the use of a fully three-dimensional (3D) PET applied to imaging of adsorption of ${ }^{11} \mathrm{CO}_{2}$ tracer gas, validating the measurement by conventional exit gas analysis. Physical adsorption is a dynamic but relatively slow ( $\mathrm{mm} / \mathrm{min}$ ) [17] process, and hence within the resolution of the PET technique. By PET-imaging of the dynamics of $\mathrm{CO}_{2}$ adsorption, the study aimed at (i) proving the application of 3D PET to dynamic systems in opaque equipment; (ii) validating PET results against $\mathrm{CO}_{2}$ concentration measurements at the discharge from the column; while (iii) also measuring time-dependent properties of the adsorption. Neither the progress of the adsorption front along the bed length nor the evolution of the Mass Transfer Zone (MTZ) can be determined using the outflow $\mathrm{CO}_{2}$ concentrations only, but both can be clearly determined by in-situ PET imaging. Such high-pressure operation is characteristic of pre-combustion $\mathrm{CO}_{2}$ capturing processes. It also expands the single previous one-dimensional application [16] to a fully 

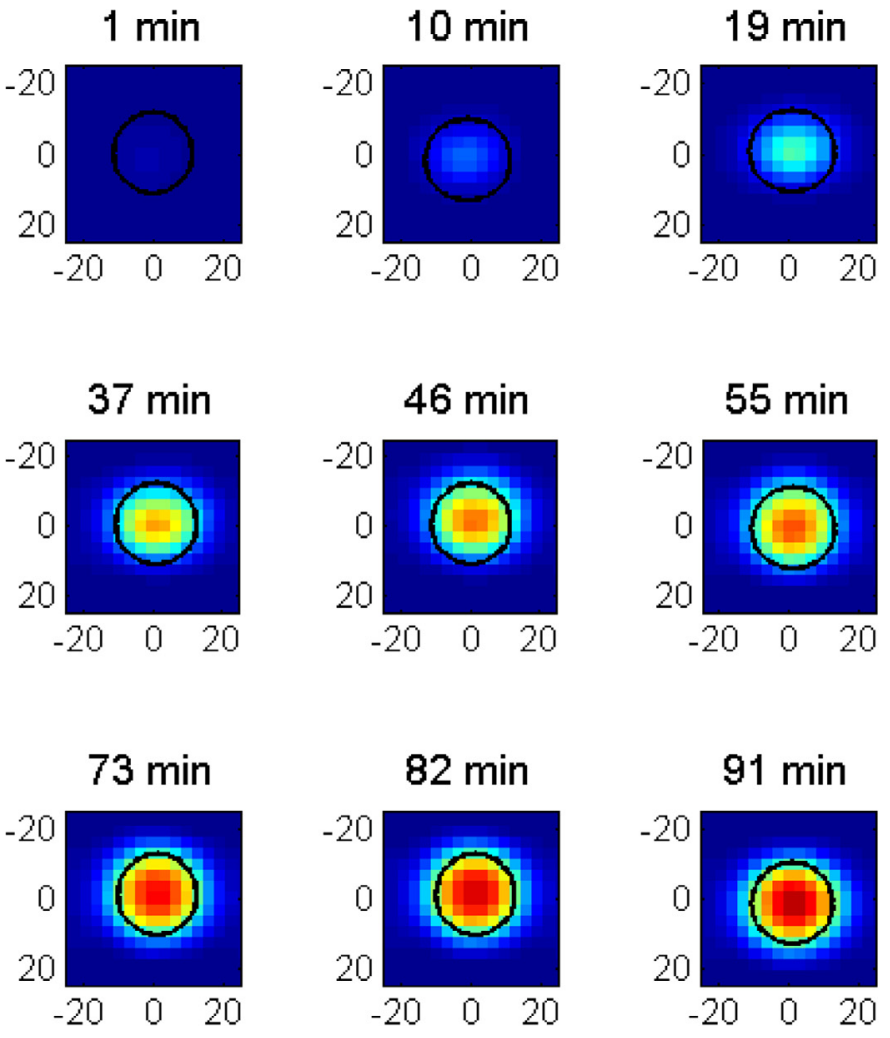

3D imaging. To achieve these aims, ${ }^{11} \mathrm{CO}_{2}$ gas was used to demonstrate and validate the PET concept and to study gas-solid adsorption. We anticipate our work to foster further studies of gas-solid systems of adsorption, gas-solid catalysis, gas-solid hydrodynamics, and processes where the gas-solid interaction is of primary importance.

\section{PET principles}

As a non-invasive imaging technique, PET can provide 3D tomography images in real-time of a radio-active tracer distribution and give quantitative information on both position and concentration. Positron emission particle tracking was previously and successfully applied when using a particle-labelled tracer, in various liquid-solid [8-12,18] and gas-solid applications [5,6,19-22]. Many reactant molecules can be labelled with short half-life time $\left(t_{0.5}\right)$ positron-emitting nuclides of carbon $\left({ }^{11} \mathrm{C}, \mathrm{t}_{0.5}=20.4 \mathrm{~min}\right)$, nitrogen $\left({ }^{13} \mathrm{~N}, 9.96 \mathrm{~min}\right)$ and oxygen $\left({ }^{15} \mathrm{O}, 2.07 \mathrm{~min}\right)$. These short $\mathrm{t}_{0.5}$ values are advantageous from the point of view of safety and ease of use but imply that PET experiments and the radionuclide production facility (a cyclotron in the present case) must be physically close. Experiments only require very small amounts of labelled molecules ( $\sim 10^{-13}$ to $10^{-12} \mathrm{~mol}$ ) since such nuclides have a high initial specific activity. Each positron emitted during the decay of the radioisotope annihilates with an electron [3], and produces 2 backto-back (collinear) high-energy $(511 \mathrm{KeV})$ gamma rays. The PET camera detects the $\gamma$-rays, allowing absolute positron-emitter concentrations to be determined, thus providing 'images' of interactions as a function of time and location. In standard medical PET imaging, data are gathered and presented in 2D planes. For complete 3D PET [2], scanners with retractable septa can acquire coincidences between all possible pairs of detectors, resulting in full 3D imaging, which is becoming more widely used in medical applications. Principles and important characteristics of the PET systems are given in Supplementary Information SI-A.

The intrinsic spatial resolution of PET imaging systems is related to geometry, specifically the centre separation of individual detector blocks. In the camera used in this study (Field of View, FOV: axial $=c 160 \mathrm{~mm}$; trans-axial $=c 400 \mathrm{~mm}$ ) the manufacturer's stated

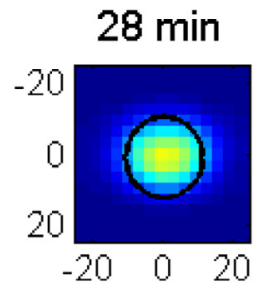

Fig. 3. Illustration of cross-sectional concentration profiles in a plane, in the middle of the adsorbent bed for Zeolite $13 \mathrm{X}$ at $1.6 \mathrm{MPa}$ and $\mathrm{C}_{\max }=10 \%$ at nine minute intervals. ${ }^{11} \mathrm{CO}_{2}$ was initially detected in the plane at time $=1 \mathrm{~min}$. The final image is the time when the plane reaches its maximum intensity, corresponding to its saturation [13].
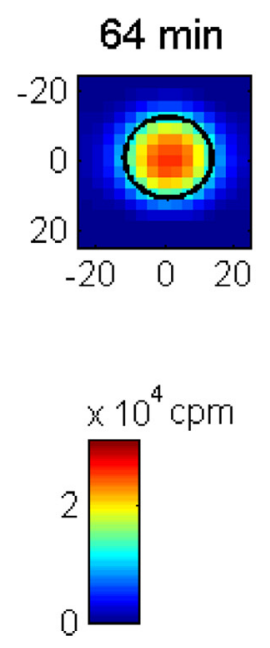

resolution is $6 \mathrm{~mm}$, close to the axis. Calibration tests of this camera with single and multiple point sources showed peaks with Full-Width at Half Maximum (FWHM) circa $10 \mathrm{~mm}$ and a peak resolution of $1 \mathrm{~mm}$ (see SI-A). In practice, the resolution achieved depends on tracer activity (limited by the saturation capacity of the detection system) and the duration of acquisition per measurement. In dynamic systems, the balance struck between spatial and temporal resolution will also depend on the rate of passage of the tracer. Blurring of the adsorption front is inherent in the technique but we have shown that with the front moving at between 0.8 and $5.4 \mathrm{~mm} /$ minute the data acquisition time of $45 \mathrm{~s}$ enables us to capture the breakthrough curve with reasonable accuracy, as shown further in the text (see Fig. 4 for examples) and we would expect the same accuracy for adsorption profiles within the bed.

\section{Experimental set-up and procedures}

Physical adsorption is a dynamic but relatively slow ( $\mathrm{mm} / \mathrm{min})$ [17] process, and hence within the resolution of the PET technique. In-situ PET-imaging of the dynamics of $\mathrm{CO}_{2}$ adsorption could determine the progress of the adsorption front along the bed length and the evolution of the Mass Transfer Zone (MTZ), which cannot be determined using the outflow $\mathrm{CO}_{2}$ concentrations only. The ${ }^{11} \mathrm{CO}_{2}$ tracer is produced on site by a cyclotron, as explained further below.

\subsection{Experimental set-up}

A stainless steel adsorption column (19 mm I.D., $22 \mathrm{~mm}$ O.D.) (Fig. 1) was packed in its centre with an adsorbent to a maximum layer length of $195 \mathrm{~mm}$ but mostly limited to an adsorbent bed length between 70 and $90 \mathrm{~mm}$ for the experiments. At each end of the adsorbent bed, $3 \mathrm{~mm}$ glass beads were inserted between steel mesh to position the adsorption bed and uniformly distribute the gas flow. The full set-up was located within the Field of View (FoV) of the PET camera. The gas exhaust was to a flexible duct which was shielded and able to contain the ${ }^{11} \mathrm{CO}_{2}$-loaded exhaust. The imaging system was confined in a lead enclosure. 

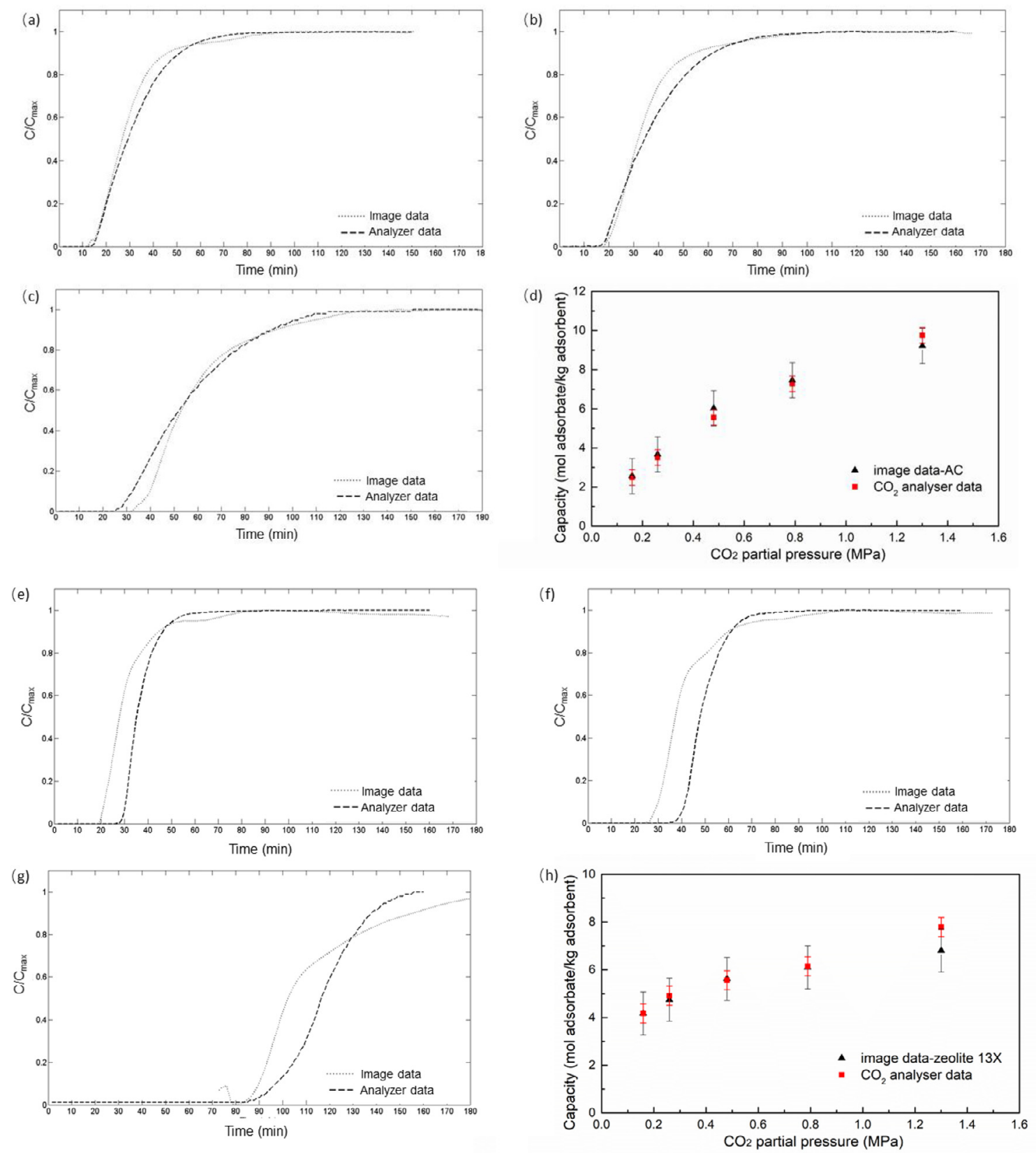

Fig. 4. Breakthrough curves from $\mathrm{PET}$ and $\mathrm{CO}_{2}$ analyser data. PET information was obtained at the outlet of the adsorption column: the total cpm for each pixel in the transverse slice was summed for each final frame. AC: (a) $\mathrm{CO}_{2}$ concentration of $50 \%$, partial $\mathrm{CO}_{2}$ pressure $1.3 \mathrm{MPa}$; (b) $\mathrm{CO}_{2}$ concentration of $30 \%$, $0.78 \mathrm{MPa}$; (c) $\mathrm{CO}_{2}$ concentration of $10 \%, 0.26 \mathrm{MPa}$. Zeolite $13 \mathrm{X}$ : (e) $\mathrm{CO}_{2}$ concentration of $50 \%, 1.3 \mathrm{MPa}$; (f) $\mathrm{CO}_{2}$ concentration of $30 \%, 0.78 \mathrm{MPa}$; (g) $\mathrm{CO}_{2}$ concentration of $10 \%$, $0.26 \mathrm{MPa}$. Figures (d) and (h) illustrate the fair agreement obtained between PET and $\mathrm{CO}_{2}$ probe measurements for both AC and Zeolite $13 \mathrm{X}$.

The $\mathrm{CO}_{2}$ and $\mathrm{N}_{2}$ (or ${ }^{11} \mathrm{CO}_{2}-\mathrm{N}_{2}$ ) feed flow rates were set by two mass flow controllers (maximum 100 and $400 \mathrm{Nml} / \mathrm{min}$, respectively, and able to withstand to a pressure of maximum $10 \mathrm{MPa}$ ). The operating system pressure was set by a backpressure regulator $P_{4}$, operated up to 2.6 MPa at $19^{\circ} \mathrm{C}$. The feed flow was also equipped with pressure gauges and regulators $\left(P_{1}, P_{2}\right.$ and $\left.P_{3}\right)$. A Servomex 5200 was used to measure $\mathrm{CO}_{2}$ concentrations at the discharge from the column, with an accuracy of $\pm 0.1 \mathrm{vol} \% \mathrm{CO}_{2}$.

\subsection{Parameters and materials}

The positron $\left(\beta^{+}\right)$emitting isotope, ${ }^{11} \mathrm{C}\left(\mathrm{t}_{0.5}=20.5 \mathrm{~min}\right)$ can be used for PET imaging. Its production involved bombarding Nitrogen-14 atoms with protons in a cyclotron [13]. Upon collision of a proton with a nitrogen atom, the proton energy can cause the release of an alpha particle, hence giving rise to the ${ }^{14} \mathrm{~N}(\mathrm{p}, \alpha){ }^{11} \mathrm{C}$ reaction. If minor amounts of oxygen are mixed with the nitrogen gas target, ${ }^{11} \mathrm{CO}_{2}$ is produced. Chemically, ${ }^{11} \mathrm{CO}_{2}$ and $\mathrm{CO}_{2}$ behave in an identical manner. The PET test gas is predominantly $\mathrm{N}_{2}$ containing minor amounts (vol-ppb) of ${ }^{11} \mathrm{CO}_{2}$.

PET experiments lasted two hours at a rate of one frame/ $45 \mathrm{sec}$. Flow rates and concentrations of $\mathrm{CO}_{2}{ }^{-1}{ }^{11} \mathrm{CO}_{2}$ applied are given in the experimental procedure below.

Further to an objective multi-criteria assessment, as described in Supplementary Information SI-B, both Zeolite 13X beads (Sigma Aldrich, USA) of average diameter $3 \mathrm{~mm}$, pore diameter $0.1 \mathrm{~nm}$ and surface area $750 \mathrm{~m} 2 / \mathrm{g}$, and Activated Carbon pellets (Brownell's, UK) of average diameter $6.5 \mathrm{~mm}$, pore diameter $<50 \mathrm{~nm}$ and surface area 800-1200 m2/g were the selected adsorbents for the research. 
(A) Intensity profiles along the adsorbent bed at different feed concentration of $\mathrm{CO}_{2}$
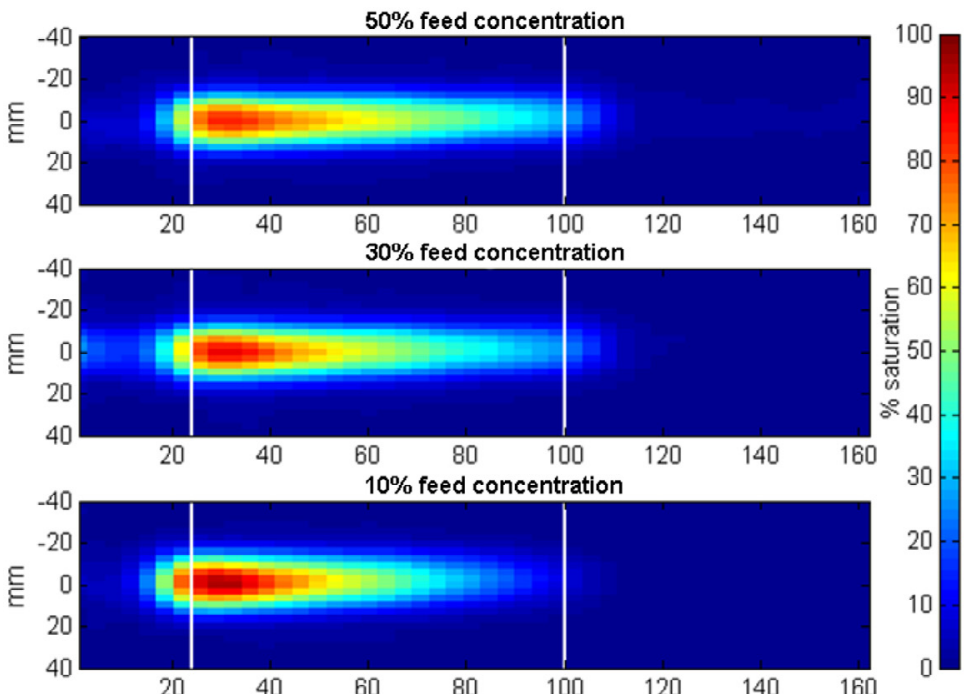

(B) Intensity profiles and evolution of the MTZ along the adsorbent bed at $30 \mathrm{vol} \% \mathrm{CO}_{2}$ feed
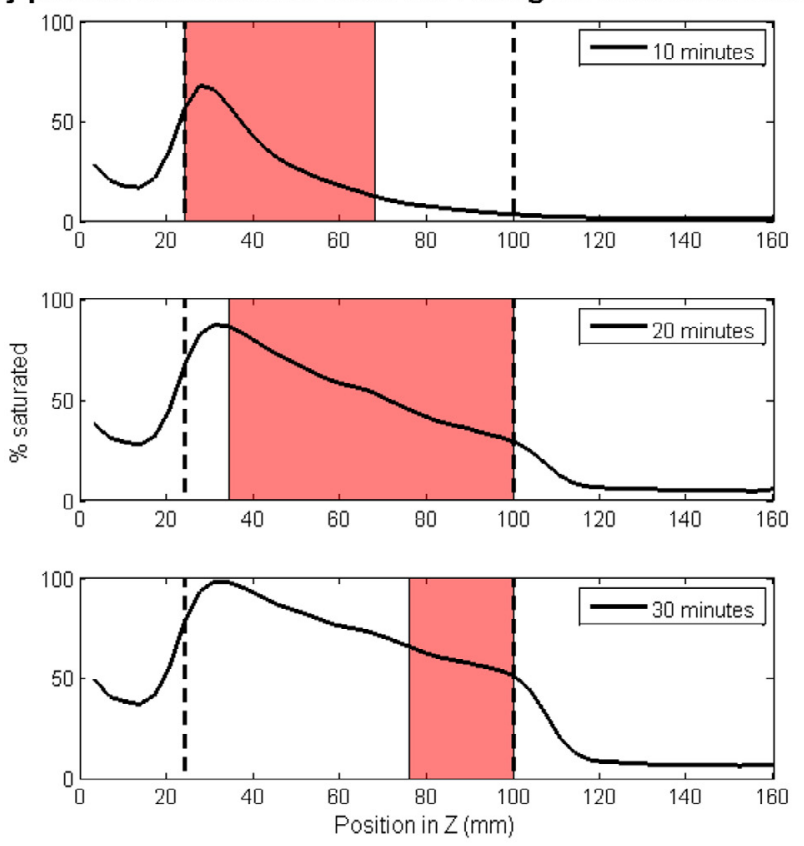

(C) wave function along the adsorbent bed at $30 \mathrm{vol} \% \mathrm{CO}_{2}$ feed

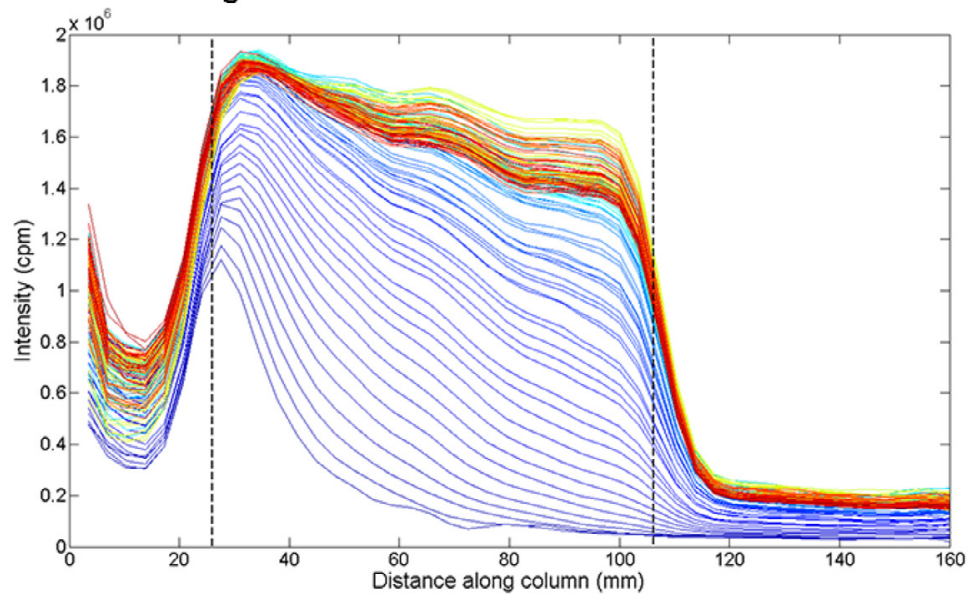

Fig. 5. Intensity profiles and wave function along the adsorbent bed of Activated Carbon (79 mm adsorbed length: 24 to $103 \mathrm{~mm}$ ) at $1.6 \mathrm{MPa}$ (Full data are given in SI-C.1). 
Table 1

Deviation, in \%, $\left(\frac{\text { PET data }-\mathrm{CO}_{2}}{\mathrm{PET}} \frac{\text { analyser data }}{\text { data }}\right)$, of data acquired by PET-imaging and $\mathrm{CO}_{2}$-analyzer.

\begin{tabular}{lllllll}
\hline $\begin{array}{l}\mathrm{CO}_{2} \text { Partial pressure } \\
(\mathrm{MPa})\end{array}$ & \multicolumn{2}{c}{$\mathrm{mol} \mathrm{CO}_{2} / \mathrm{kg} \mathrm{AC}$} & \multicolumn{4}{c}{$\mathrm{mol} \mathrm{CO}_{2} / \mathrm{kg}$ Zeolite $13 \mathrm{X}$} \\
\cline { 2 - 7 } & PET & Analyser & $\%$ & PET & Analyser & $\%$ \\
\hline 0.159 & 2.560 & 2.485 & 2.90 & 4.173 & 4.173 & 0.00 \\
0.259 & 3.672 & 3.505 & 4.55 & 4.748 & 4.915 & -3.52 \\
0.480 & 6.028 & 5.564 & 7.69 & 5.620 & 5.564 & 0.99 \\
0.789 & 7.465 & 7.280 & 2.48 & 6.102 & 6.148 & -0.76 \\
1.301 & 9.218 & 9.756 & -5.84 & 6.807 & 7.790 & -14.44 \\
\hline
\end{tabular}

\subsection{Experimental procedure}

The experimental procedure involved several stages. During the regeneration of the bed (1-3 h), pure $\mathrm{N}_{2}$ was used to flush the bed at $200 \mathrm{Nml} / \mathrm{min}$. The $\mathrm{CO}_{2}$ analyser was then started to measure the vol\% $\mathrm{CO}_{2}$ at the column exit. The system pressure was increased to and maintained at 2.6 MPa for most of the experiments. The ${ }^{11} \mathrm{CO}_{2}-\mathrm{N}_{2}$ cyclotron gas cylinder was connected and pressurised at about $6 \mathrm{MPa}$ by adding $\mathrm{N}_{2}$. When at this pressure, both ${ }^{11} \mathrm{CO}_{2}-\mathrm{N}_{2}$ and $\mathrm{CO}_{2}$ were fed at the STP flow rates defined before, and the PET imaging was performed. For both Zeolite 13X and Activated Carbon, the total operating pressure was 2.6 MPa for most of the experiments. The partial pressure of $\mathrm{CO}_{2}$ is a function of its vol\% (10 to 50). The $\mathrm{N}_{2}$ flow was $140 \mathrm{Nml} \mathrm{min}^{-1}$ with

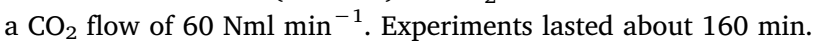

Finally, $\mathrm{CO}_{2}$ and $\mathrm{N}_{2}$ supplies were turned off and the rig was slowly depressurized. Radioactive tracer would continue to be exhausted to the expandable and shielded ducting pipe for overnight decay. When at ambient pressure, the tracer gas cylinder was removed and returned to the cyclotron to be used in the next experiment.

All flow, images and $\mathrm{CO}_{2}$ concentration data where thereafter processed to assess the $\mathrm{CO}_{2}$ adsorption. Adsorption kinetics and breakthrough curves were generated and compared with experimental imaging data. The images captured were reconstructed by the Unix PET computer, transformed to usable image files (jpg/png format), and numerically analysed.

\subsection{Data treatment for adsorption}

In adsorption of gaseous components on a solid substrate, various parameters are important to characterize the process and progress, i.e. the mass transfer zone, the adsorption equilibrium as commonly determined by the rate of transfer of adsorbate onto adsorbent to reach equilibrium conditions, and the adsorption mechanisms, which are expected to be diffusion dominated. These parameters are defined and described in Supplementary information SI-C and SI-D.

\section{Experimental results and discussion}

\subsection{Profiles of the tracer concentration with time and length}

Fig. 2 illustrates eleven consecutive image frames, from the initial ${ }^{11} \mathrm{CO}_{2}$ arrival (frame 1). The highest concentration region in the adsorption bed is shown by red pixels (determined from the relative intensity of the tracer in counts/min). With increasing time, $\mathrm{CO}_{2}$ becomes uniformly adsorbed throughout the bed length as shown in frame 11 (after $495 \mathrm{~s}$ ).

A similar progress of the adsorption is shown in the cross-sectional intensity profiles of accumulated ${ }^{11} \mathrm{CO}_{2}$ at a given cross section within the bed, is illustrated in Fig. 3. The experiments demonstrate varying adsorption front velocities using different intensity values, and indicate that $\mathrm{CO}_{2}$ was still adsorbed even after the main Mass Transfer Zone (MTZ) moved past the given location. The comparison of the accumulation rate of $\mathrm{CO}_{2}$ at a given location with the bulk velocity of the MTZ enabled the determination of the overall mass transfer kinetics, as illustrated in SI-D.

\subsection{Breakthrough curves}

Both PET results, and measurements by the $\mathrm{CO}_{2}$ probe at the bed exit, were used to construct the breakthrough curves.

Fig. 4 illustrates the resulting breakthrough curve for Activated Carbon and Zeolite $13 \mathrm{X}$ at various $\mathrm{CO}_{2}$ concentrations. The curves clearly show a zero output concentration until about 15 (high $\mathrm{CO}_{2}$ ) to 30 (low $\mathrm{CO}_{2}$ ) minutes which corresponds with a MTZ progress in the bed at a bulk velocity of 13 and $6.5 \mathrm{~mm} \mathrm{~min}^{-1}$, respectively. The curves level off after respectively $\sim 120$ and $\sim 60 \mathrm{~min}$. Both factors confirm that a PET frame acquisition duration of $45 \mathrm{~s}$ is certainly suitable, since meeting the measured Full-Width at Half Maximum (FWHM), as illustrated in SI-A. Fig. 5 summarizes both the image and the analyser data, for different experimental conditions. Good agreement is obtained and the times to breakthrough only differ by about $5 \mathrm{~min}$. Data at $50 \%$ and $30 \%$ feed concentrations show a different initial inclination, slightly steeper, however with negligible differences in the observed times to saturation (6 and $1 \mathrm{~min}$, respectively).

To compare the $\mathrm{CO}_{2}$ PET imaging and probe results; data of Fig. 4(d) and 4(h) were summarized in Table 1, with deviations amongst respective data expressed in \%. For most of the $\mathrm{CO}_{2}$ partial pressures, the respective error bars of the average data overlap and deviations are generally positive or negative, within the accuracy margin of 5 to $10 \%$ as expected from the accuracy of the Servomex $\mathrm{CO}_{2}$ probe and the spatial resolution of the PET imaging. This fair agreement is not obtained for Zeolite $13 \mathrm{X}$ at the highest partial pressure of $\mathrm{CO}_{2}$ (1.3 MPa): the average PET result is $14.44 \%$ lower than the $\mathrm{CO}_{2}$ probe result. This higher deviation is probably due to the length and the location of the Zeolite 13X adsorber bed ( $69 \mathrm{~mm}$ only, not centrally positioned along the FoV. and hence responsible for an attenuation error correction of the PET camera). This error only occurred at high $\mathrm{CO}_{2}$ partial pressures, where the velocity front moves faster than at lower pressures (as discussed below). Ideally, the location of the adsorbents should be centrally towards the FoV. This Zeolite $13 \mathrm{X}$ data point should hence be considered with caution.

\subsection{Mass transfer zone}

The in-bed progress of the adsorption phenomenon as described in Supplementary Information B-1 can only be observed by PET imaging.

Figs. 5 and 6 show central cross sectional images along the length of the column for adsorption on AC and Zeolite 13X, respectively, at a reference $20 \mathrm{~min}$ of operation and for different $\mathrm{CO}_{2}$ feed concentrations. Pixel intensities are normalized with a pixel at maximum intensity representing $100 \%$ saturation. The illustration of concentration profiles are added at $30 \% \mathrm{CO}_{2}$ to depict the distribution of ${ }^{11} \mathrm{CO}_{2}$ along the column as \% of the maximum observed capacity. Additional figures are reported in SI-C.1. Data were moreover transferred into intensity wave functions, also completely illustrated in SI-C.1

Both intensity curves and wave functions are important to understand the adsorption kinetics.

For Activated Carbon, the MTZ is reduced progressively from $92 \mathrm{~mm}$, to $74 \mathrm{~mm}$ and $58 \mathrm{~mm}$ at respectively 50, 30 and 10 vol\% feed concentration. The velocity of the adsorption front decreases with the vol\% concentration from $5.4 \mathrm{~mm} / \mathrm{min}(50 \%), 4.14 \mathrm{~mm} / \mathrm{min}(30 \%)$ to $3.05 \mathrm{~mm} / \mathrm{min}(10 \%)$.

For Zeolite 13X, on the contrary, calculated MTZ are $40 \mathrm{~mm}$ (50 vol $\%), 26 \mathrm{~mm}$ (30 vol\%) and $16 \mathrm{~mm}$ (10 vol\%) only. The adsorption front velocities are $3.05(50 \%), 2.32(30 \%)$ and $0.78(10 \%) \mathrm{mm} / \mathrm{min}$, respectively. Clearly, Activated Carbon has a faster moving bulk adsorption front than Zeolite 13X.

This is also confirmed by the mass transfer wave velocities (SI-C.1). The concentration profiles in The wave functions of Fig. 5(C) and 6(C) 
(A) Intensity profiles along the adsorbent bed at different feed concentration of $\mathrm{CO}_{2}$
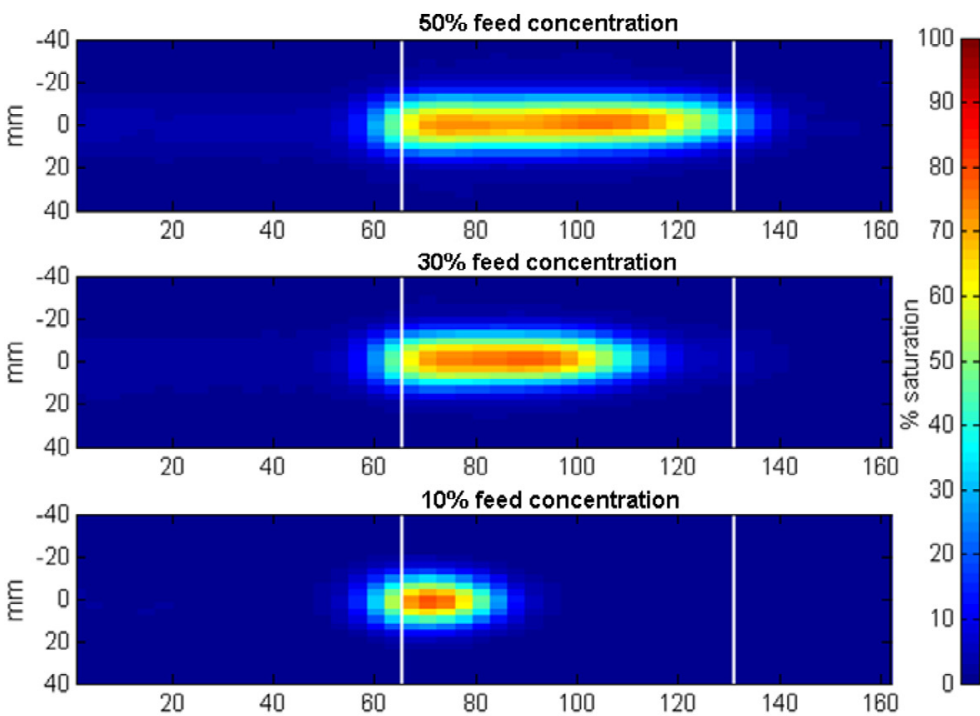

(B) Intensity profiles and evolution of the MTZ along the adsorbent bed at $30 \mathrm{vol} \% \mathrm{CO}_{2}$ feed
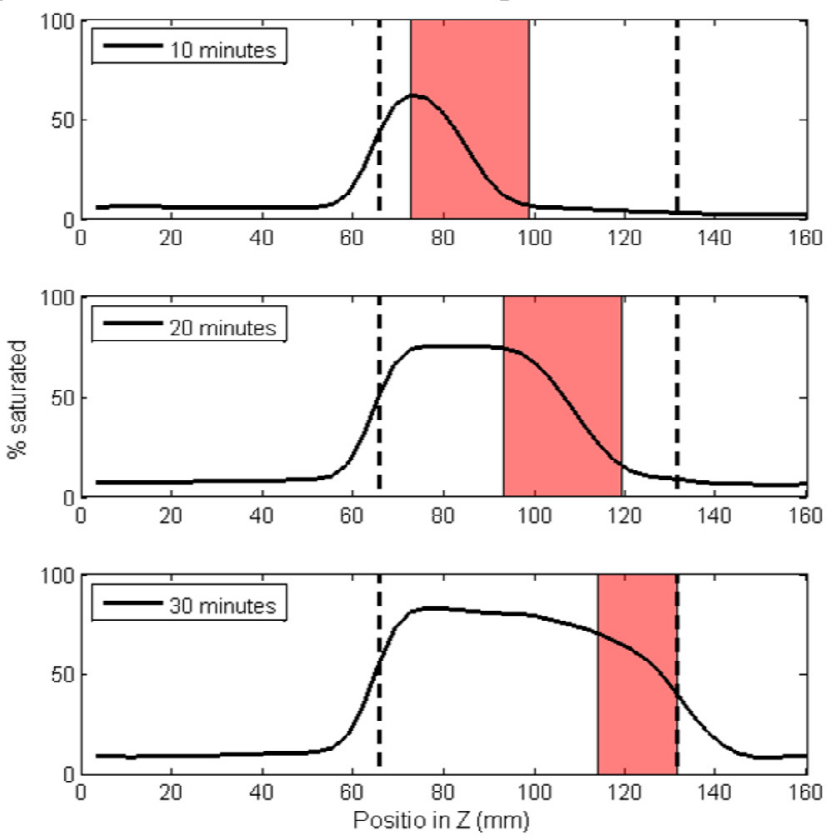

(C) wave function along the adsorbent bed at $30 \mathrm{vol} \% \mathrm{CO}_{2}$ feed

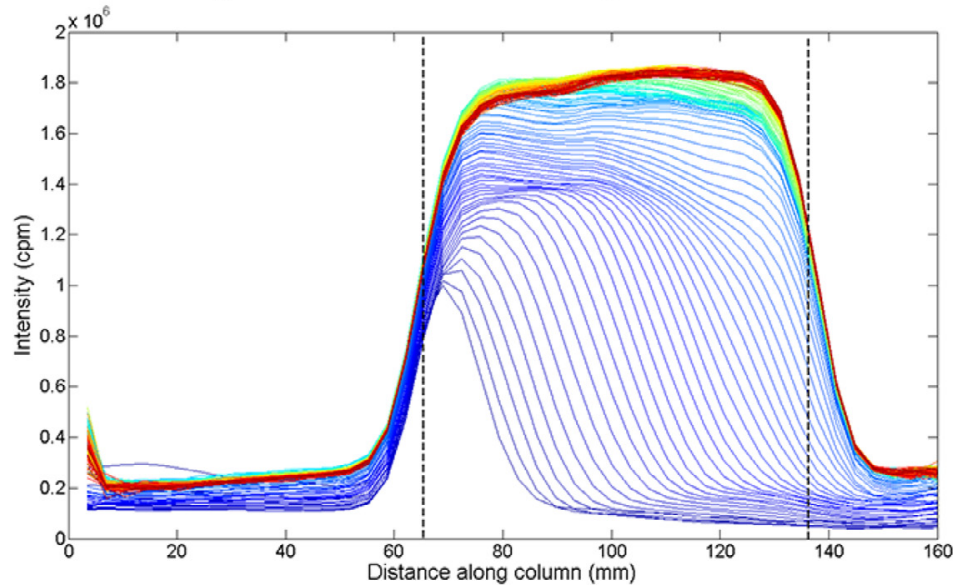

Fig. 6. Intensity profiles and wave function along the adsorbent bed of Zeolite $13 \mathrm{X}$ (69 mm adsorbed length: 66 to $135 \mathrm{~mm}$ ) at $2.6 \mathrm{MPa}$ (Full data are given in SI-C.1). 
are very close together which would imply a slow progression of the MTZ through the bed. Conversely, the concentration profiles shown in Fig. 5(B) and 6(B) are much more spaced apart and the profiles begin to plateau at about $70 \%$ of the maximum intensity. This would indicate a relatively fast moving bulk adsorption front with the entire length of the adsorption region acting as an active MTZ, with consistent ${ }^{11} \mathrm{CO}_{2}$ uptake for the length of the bed from about 19 min onwards into the experiment.

\subsection{Overall appraisal}

The results presented prove that a gaseous nuclide-based imaging technique can be used for adsorption studies and provides valuable insights into the kinetics inside the opaque packed bed column for $\mathrm{CO}_{2}$ adsorption. Imaging defines the concentration profiles and locationspecific $\mathrm{CO}_{2}$ accumulation, the progress and velocity of the adsorption front along the column length, and finally the MTZ. The number of events detected was corrected for decay and sensitivity by calibration, and is proportional to the ${ }^{11} \mathrm{CO}_{2}$ concentration. The velocity of the adsorption front increased with the increasing partial pressure of $\mathrm{CO}_{2}$ being fed to the adsorber bed.

As stated before, adsorption design equations are mostly based upon the concentration of the adsorbed component in the adsorber exit gas stream, thus defining overall adsorption parameters such as adsorption efficiency expressed in mole of adsorbate per $\mathrm{kg}$ of adsorbent, or the expected time to achieve the breakthrough of adsorbate from the adsorbent. Dynamic measurements inside the adsorbent bed are seldom performed, although they are extremely important to measure the adsorption kinetics and MTZ through the evolution of concentrations with time and location. Asif [23] and Medeiros [24] mentioned that the lack of these data does not allow to validate 2D or Computational Fluid Dynamics (CFD) simulation results, respectively. Windes et al. [25] estimated concentrations in an exothermic packed bed reactor by measuring the temperature profile (with only one or two properly placed temperature sensors). Finally, Mustafa [26] developed a special probe to collect gas samples along the reactor, with stored gas samples subsequently analyzed by GC/MS. This measurement technique does not provide rezal-time data, since samples are analyzed after the tests only. The advantages of the PET imaging are hence evident, since providing real-time concentration profile data.

\section{Application of the experimental data to validate gas adsorption models and theories}

$\mathrm{CO}_{2}$ analysis data were further used to validate kinetic adsorption theories, as described in detail in Supplementary Information SI-D.

The data treatment confirms that PET measurements provides in-situ data that enable a full theoretical treatment of adsorption. A pseudofirst-order model provides a fair linear fitting of predicted and experimental results for both adsorbents tested, and can hence be applied for further calculations. As far as adsorption mechanisms are concerned, intra-particle diffusion is rate-limiting for Activated Carbon, while for Zeolite 13X both film and intra-particle diffusion must be considered.

\section{Conclusions}

The results have proven that PET can be used as a non-invasive radio-active gas imaging technique in opaque systems. The additional 3D information it gives, including the shape of the mass transfer zone, enables fundamental insights into the kinetics of packed bed $\mathrm{CO}_{2}$ adsorption.

The scientific potential of the imaging technique in opaque systems was demonstrated by using the data obtained, with the various literature approaches for gas adsorption. Here too, PET imaging data can be applied and help to select the most appropriate approaches for the studied $\mathrm{CO}_{2} /$ Zeolite $13 \mathrm{X}$ or Activated Carbon process.
To further develop and implement the PET investigation concept, additional research is recommended to include (i) the kinetic study of desorbing ${ }^{11} \mathrm{CO}_{2}$ at reduced pressure and after system saturation has been reached; examining 3D-surface gas-solid catalytic reactions in e.g. car exhausts [16], fixed bed reactions such as encountered in mineral oxides $/ \mathrm{CO}_{2}$ carbonation/decarbonation cycles [17], catalytic and noncatalytic deNO ${ }_{\mathrm{x}}$ [27] and $\mathrm{deSO}_{\mathrm{x}}$ [28], or the immobilisation behaviour of bio-molecules on an appropriate carrier $[29,30]$. Even complex mechanisms of PCDD/F removal [31-33] in fixed, entrained or moving beds, and/or PCDD/F catalytic destruction on $\mathrm{V}_{2} \mathrm{O}_{5} / \mathrm{NO}_{3} / \mathrm{TiO}_{2}$ catalyst [34] could be elucidated. To improve the temporal resolution of the PET imaging, the Positron Imaging Centre at The University of Birmingham has recently acquired a GE Discovery ST scanner with similar FOV and spatial resolution but improved sensitivity which should offer greater temporal resolution. For smaller scale studies a Concord P4 (FOV: axial $150 \mathrm{~mm}$; trans-axial $80 \mathrm{~mm}$ ) with stated resolution of $1.8 \mathrm{~mm}$ will also be available.

Finally, the technique offers potential application in various other fields, since also $\mathrm{N}$ and $\mathrm{O}$ positron emission isotopes can be used (albeit with a lower half-life time).

\section{Declaration of Competing Interest}

The authors declare that they have no known competing financial interests or personal relationships that could have appeared to influence the work reported in this paper.

\section{Acknowledgements}

Authors acknowledge funding from the Beijing Advanced Innovation Centre of Soft Matter Science and Engineering (Beijing University of Chemical Technology, China).

\section{Contributions}

J.P.K.S. and Y.M.D. have equally shared the main scientific tasks, and should both be considered as equal primary authors. A.I., L.T., S.D.B. and J.P.K.S. designed and assembled the experimental rig. A.I., S.D.B. and L.T. performed the PET tests with ${ }^{11} \mathrm{CO}_{2}$ tracer gas, itself generated in the cyclotron of the Birmingham University. P.D. and J.B. performed the risk assessment. Y.M.D., L.A., J.B. and H.L.Z. looked into the fundamentals of adsorption, and were assisted by R.D. and R.A. for the data interpretation and treatment. Y.M.D., J.B., R.D. and H.L.Z. drafted the work, while all co-authors substantially participated in the edition of the final manuscript.

\section{Appendix A. Supplementary data}

Supplementary data to this article can be found online at https:// doi.org/10.1016/j.cej.2020.126507.

\section{References}

[1] G. Muehllehner, J.S. Karp, Positron emission tomography, Phys. Med. Biol. 51 (2006) R117-R137, https://doi.org/10.1088/0031-9155/51/13/R08.

[2] D. Parker, C. Wheldon, The Birmingham MC40 cyclotron facility, Nucl. Phys. News. 28 (2018) 15-20, https://doi.org/10.1080/10619127.2018.1463021.

[3] C.R.K. Windows-Yule, J.P.K. Seville, A. Ingram, D.J. Parker, Positron emission particle tracking of granular flows, Annu. Rev. Chem. Biomol. Eng. 11 (2020) 367-396, https://doi.org/10.1146/annurev-chembioeng-011620-120633.

[4] P. Allport, M. Baca, D. Briglin, J. Broughton, R. Canavan, A. Chisholm, L. Gonella, P. Knights, K. Nikolopoulos, D. Parker, T. Price, J. Thomas, J. Wilson, A. Affolder, G. Casse, P. Dervan, A. Greenall, I. Tsurin, S. Wonsak, S. Dixon, S. Edwards, R. French, P. Hodgson, P. Kemp-Russell, E. Kourlitis, H. Marin-Reyes, K. Parker, Recent results and experience with the Birmingham MC40 irradiation facility, J. Instrum. 12 (2017) c03075, , https://doi.org/10.1088/1748-0221/12/03/C03075.

[5] H.L. Zhang, T. Gowing, J. Degrève, T. Leadbeater, J. Baeyens, The use of particle heat carriers in the Stirling engine concept, Energy Technol. (2016), https://doi. org/10.1002/ente.201500274. 
[6] S. Mahmoudi, J.P.K. Seville, J. Baeyens, The residence time distribution and mixing of the gas phase in the riser of a circulating fluidized bed, Powder Technol. (2010), https://doi.org/10.1016/j.powtec.2010.05.024.

[7] S.D. Bell, A. Ingram, T.W. Leadbeater, D.J. Parker, An investigation into the feasibility of radioactive gas imaging for studies in process tomography, in: 7th World Congr. Ind. Process Tomogr., 2014. https://doi.org/https://www.isipt.org/worldcongress/7/933.html.

[8] K.E. Waters, N.A. Rowson, X.F. Fan, D.J. Parker, J.J. Cilliers, The use of positron emission particle tracking as a method for tracking particles in flotation froths, Philos. Mag. Lett. 88 (2008) 735-1539, https://doi.org/10.1080/ 09500830802203394.

[9] O. Mihailova, D. O'Sullivan, A. Ingram, S. Bakalis, Velocity field characterization of Newtonian and non-Newtonian fluids in SMX mixers using PEPT, Chem. Eng. Res. Des. 108 (2016) 126-138, https://doi.org/10.1016/j.cherd.2016.03.006.

[10] W.D. Griffiths, Y. Beshay, A.J. Caden, X. Fan, J. Gargiuli, T.W. Leadbeater D.J. Parker, The use of positron emission particle tracking (PEPT) to study the movement of inclusions in low-melting-point alloy castings, Metall. Mater. Trans. B 43 (2011) 370-378, https://doi.org/10.1007/s11663-011-9596-0.

[11] M.J.H. Simmons, I. Edwards, J.F. Hall, X. Fan, D.J. Parker, E.H. Stitt, Techniques for visualization of cavern boundaries in opaque industrial mixing systems, AIChE J. (2009), https://doi.org/10.1002/aic.11889.

[12] W.D. Griffiths, Y. Beshay, D.J. Parker, X. Fan, The determination of inclusion movement in steel castings by positron emission particle tracking (PEPT), J. Mater. Sci. 43 (2008) 6853-6856, https://doi.org/10.1007/s10853-008-2999-x.

[13] S.D. Bell, The development of radioactive gas imaging for the study of chemical flow processes, University of Birmingham, School of Chemical Engineering, College of Engineering and Physical Sciences, retrieved from http://etheses.bham.ac.uk/id/ eprint, 2015. http://etheses.bham.ac.uk/id/eprint/6545.

[14] C. Dechsiri, A. Ghione, F. van de Wiel, H.G. Dehling, A.M.J. Paans, A.C. Hoffmann, Positron Emission Tomography Applied to Fluidization Engineering, Can. J. Chem. Eng. 83 (2005) 88-96, https://doi.org/10.1002/cjce.5450830116.

[15] T. Barth, J. Kulenkampff, M. Ludwig, S. Bras, M. Gründig, K. Franke, Study of particle deposition and resuspension in pebble beds using positron emission tomography, in: 7th World Congr. Ind. Process Tomogr., 2013: pp. 2-5.

[16] G. Jonkers, K.A. Vonkeman, S.W.A. Van Der Wal, R.A. Van Santen, Surface catalysis studied by in situ positron emission, Nature 355 (1992) 63-66, https://doi.org/10. 1038/355063a0.

[17] J. Liu, J. Baeyens, Y. Deng, T. Tan, H. Zhang, The chemical CO2 capture by carbonation-decarbonation cycles, J. Environ. Manage. 260 (2020) 110054.

[18] A. Guida, X. Fan, D.J. Parker, A.W. Nienow, M. Barigou, Positron emission particle tracking in a mechanically agitated solid-liquid suspension of coarse particles, Chem. Eng. Res. Des. 87 (2009) 421-429, https://doi.org/10.1016/j.cherd.2008. 12.001 .

[19] Z. Yang, X. Fan, P.J. Fryer, D.J. Parker, S. Bakalis, Improved multiple-particle tracking for studying flows in multiphase systems, AIChE J. 53 (2007) 1941-1951, https://doi.org/10.1002/aic.11224.
[20] M. Van de Velden, J. Baeyens, J.P.K. Seville, X. Fan, The solids flow in the riser of a Circulating Fluidised Bed (CFB) viewed by Positron Emission Particle Tracking (PEPT), Powder Technol. 183 (2008) 290-296, https://doi.org/10.1016/j.powtec. 2007.07.027.

[21] X. Fan, D.J. Parker, Z. Yang, J.P.K. Seville, J. Baeyens, The effect of bed materials on the solid/bubble motion in a fluidised bed, Chem. Eng. Sci. 63 (2008) 934-950, https://doi.org/10.1016/j.ces.2007.06.045.

[22] Y. Xu, T. Li, L. Lu, X. Gao, S. Tebianian, J.R. Grace, J. Chaouki, T.W. Leadbeater, R. Jafari, D.J. Parker, J. Seville, N. Ellis, Development and confirmation of a simple procedure to measure solids distribution in fluidized beds using tracer particles, Chem. Eng. Sci. 217 (2020) 115501, , https://doi.org/10.1016/j.ces.2020.115501.

[23] M. Asif, Conversion enhancement of fixed-bed reactors using two-dimensional hollow cylindrical catalyst pellet, Int. J. Chem. React. Eng. 11 (1) (2013) 159-168, https://doi.org/10.1515/ijcre-2012-0038.

[24] N.J. Medeiros, Computational Fluid Dynamics Simulations of Radial Dispersion in Low N Fixed Bed Reactors. (2015) Worcester Polytechnic Institute, Masters Theses 1306, retrieved from https://digitalcommons.wpi.edu/etd-theses/1306/.

[25] L.C. Windes, A. Cinar, W.H. Ray, Dynamic estimation of temperature and concentration profiles in a packed bed reactor, Chem. Eng. Sci. 44 (10) (1989) 2087-2106, https://doi.org/10.1016/0009-2509(89)85144-9.

[26] M. Yalin, Investigation of concentration profiles in carbon nanotube production reactor. (2009) ODTÜ METU, Open METU, retrieved from http://citeseerx.ist.psu. edu/viewdoc/download?doi $=10.1 .1 .632 .8443 \&$ rep $=$ rep1\&type $=$ pdf (retrieved on 10 July 2020 )

[27] S. Mahmoudi, J. Baeyens, J.P.K. Seville, NO x formation and selective non-catalytic reduction (SNCR) in a fluidized bed combustor of biomass, Biomass and Bioenergy 34 (2010) 1393-1409, https://doi.org/10.1016/j.biombioe.2010.04.013.

[28] Deng, Ansart, Baeyens, Zhang, Flue gas desulphurization in circulating fluidized beds, Energies. 12 (2019) 3908. doi: 10.3390/en12203908.

[29] D. Moelans, P. Cool, J. Baeyens, E.F. Vansant, Immobilisation behaviour of biomolecules in mesoporous silica materials, Catal. Commun. 6 (2005) 591-595, https://doi.org/10.1016/j.catcom.2005.05.007.

[30] D. Moelans, P. Cool, J. Baeyens, E.F. Vansant, Using mesoporous silica materials to immobilise biocatalysis-enzymes, Catal. Commun. 6 (2005) 307-311, https://doi. org/10.1016/j.catcom.2005.02.005.

[31] K. Everaert, J. Baeyens, Removal of PCDD/F from flue gases in fixed or moving bed adsorbers, Waste Manage. 52 (2004) 1378-1388, https://doi.org/10.1016/S0956053X(03)00136-3.

[32] K. Everaert, J. Baeyens, J. Degrève, Entrained-phase adsorption of PCDD/F from incinerator flue gases, Environ. Sci. Technol. (2003), https://doi.org/10.1021/ es020020w.

[33] K. Everaert, J. Baeyens, J. Degrève, Removal of pcdd/f from incinerator flue gases by entrained-phase adsorption, J. Air Waste Manag. Assoc. 52 (2002) 1378-1388, https://doi.org/10.1080/10473289.2002.10470872.

[34] K. Everaert, Catalytic combustion of volatile organic compounds, J. Hazard. Mater. 109 (2004) 113-139, https://doi.org/10.1016/j.jhazmat.2004.03.019. 